\title{
Mechanochemical synthesis and high-capacity performances of transition-metal borides as aqueous anode materials
}

\author{
WANG YaDong $^{1 *}$, GUANG XianYong ${ }^{2} \&$ PAN Mu${ }^{1}$ \\ ${ }^{1}$ State Key Laboratory of Advanced Technology for Materials Synthesis and Processing, Wuhan University of Technology, \\ Wuhan 430070, China; \\ ${ }^{2}$ Department of Chemistry, Wuhan University, Wuhan 430072, China
}

Received November 2, 2011; accepted December 21, 2011; published online March 31, 2012

\begin{abstract}
Transition-metal borides $\mathrm{MB}_{0.5}(\mathrm{M}=\mathrm{Co}, \mathrm{Mo}, \mathrm{V})$ were synthesized by high-speed mechanical ball-milling of the corresponding elemental metals and boron, and investigated as aqueous anode materials. The as-synthesized borides can achieve an excellent discharge capacity, about twice that of their parent transition metals. The metal boride electrodes also exhibit polarizations about 100-300 mV lower than those of their parent metals. The galvanostatic discharge curve of $\mathrm{CoB}_{0.5}$ shows a single discharge voltage plateau as a result of simultaneous electro-oxidation of elemental cobalt and/or amorphous cobalt boride. $\mathrm{Both}^{\mathrm{MoB}} \mathrm{B}_{0.5}$ and $\mathrm{VB}_{0.5}$ show two well-defined voltage plateaus, corresponding to the electro-oxidation of the corresponding metal and boride. These results show that the coexisting transition metal and boride in the metal borides co-activate each other in the ball-milling process, thereby significantly enhancing their electrochemical performances.
\end{abstract}

borides, multi-electron reaction, high capacity, anode materials

Citation: Wang Y D, Guang X Y, Pan M. Mechanochemical synthesis and high-capacity performances of transition-metal borides as aqueous anode materials. Chin Sci Bull, 2012, 57: 4225-4228, doi: 10.1007/s11434-012-5070-x

Metal borides have received considerable attention recently because of their high specific capacities as anode materials in both alkaline and neutral electrolytes [1-8]. In our earlier work, crystalline $\mathrm{VB}_{2}$ was found to deliver a very high discharge capacity of above $3100 \mathrm{mAh} \mathrm{g}^{-1}$ through a simultaneous 11-electron electrochemical oxidation; this is probably the highest specific capacity observed so far for aqueous anode materials [1]. The effective electro-activation of crystalline borides represented by $\mathrm{VB}_{2}$ is attributed to at least two factors. One is the improved electronic conductivity of the boron component as a result of the alternating boron layers and transition metal (TM) layers in the $\mathrm{MB}_{2}$ lattice. The other is the synergistic effects of boron and TM: electron donation from the TM atoms to the boron atoms weakens the bonds between the boron atoms, resulting in electrochemical activation of boron. Conversely, the activation of boron alleviates the passivation of the TM and leads

\footnotetext{
*Corresponding author (email: zhaojq@iccas.ac.cn)
}

to TM activation. These activations ensure electro-oxidation of both TM and boron in the TM borides, resulting in the very high-capacity output of the borides.

To test the potential of other types of metal borides for high-capacity anode materials, we synthesized a series of $\mathrm{MB}_{0.5}(\mathrm{M}=\mathrm{Co}, \mathrm{Mo}$, and $\mathrm{V})$ by mechanical ball-milling and investigated their electrochemical properties as aqueous anodes. In this paper, we report the synthesis, polarization behaviors, and high-capacity performances of these $\mathrm{MB}_{0.5}$ compounds. The mechanisms of electrochemical activation of the borides are also discussed.

\section{Experimental}

\subsection{Preparation of $\mathrm{MB}_{0.5}$}

The $\mathrm{MB}_{0.5}$ borides $(\mathrm{M}=\mathrm{Co}, \mathrm{Mo}$, and $\mathrm{V})$ were prepared by mechanical ball-milling a mixture of the elemental TM (Co, $\mathrm{Mo}$, or $\mathrm{V}$ ) and boron powders in a TM:boron atomic ratio of 
1:0.5, using a high-energy-shaker ball-miller (QM-3A, Nanjing University Instrument Plant, China). The particle sizes of all the TM powders (Beijing Mountain Technical Development Center, China) were 200 mesh, and the purities were $99 \%$. The particle size of the boron powder (Changsha Hengrui New Material Development Co. Ltd, China) was 325 mesh, with $95 \%$ purity. The ball-milling process was performed for $20 \mathrm{~h}$ under an argon atmosphere to prevent surface oxidation. The shaker speed was set at $1200 \mathrm{r} / \mathrm{min}$. A B/C composite was synthesized in the same way, but with a weight ratio of boron to carbon of $2: 3$.

\subsection{Materials characterizations}

The as-synthesized TM borides were examined by powder X-ray diffraction (XRD) using a Shimadzu Lab XRD-6000 diffractometer with a $\mathrm{Cu} \mathrm{K} \alpha$ source. The scan speed was set at $4^{\circ} \mathrm{min}^{-1}$ and the data were collected over a scattering angle range of $2 \theta=10^{\circ}-80^{\circ}$.

The thin-film electrodes were prepared by mixing $85 \%$ boride powders, $7 \%$ polytetrafluoroethylene (in a $60 \%$ emulsion), and $8 \%$ acetylene black into a paste, and then roll-pressing the paste into films of thickness $0.15 \mathrm{~mm}$ at a temperature of $40-60^{\circ} \mathrm{C}$. The electrodes were finished by pressing the films onto stainless-steel mesh as a current collector.

Cyclic voltammetric (CV) measurements were performed in a three-electrode cell using a $3 \mathrm{~mm} \times 3 \mathrm{~mm}$ boride film electrode as the working electrode, a large-area air electrode as the counter electrode, and $\mathrm{Hg} / \mathrm{HgO}$ in the electrolyte as the reference electrode. The electrolyte was $6 \mathrm{~mol} \mathrm{~L}^{-1} \mathrm{KOH}$ aqueous solution. CV was conducted using a CHI660a electrochemical workstation.

The discharge performances of the boride electrodes were evaluated by galvanostatic discharge experiments using laboratory cells similar to those used for $\mathrm{CV}$, but with a $1 \mathrm{~cm} \times 1 \mathrm{~cm}$ boride electrode as the anode, with a battery-testing system (NEWARE BTS-610).

\section{Results and discussion}

Figure 1 compares the XRD patterns of the ball-milled $\mathrm{VB}_{0.5}$ samples with that of elemental vanadium. The as-prepared $\mathrm{VB}_{0.5}$ shows well-resolved diffraction peaks of metallic vanadium and featureless bands at $2 \theta=35^{\circ}-45^{\circ}$, reflecting the presence of elemental vanadium and amorphous vanadium boride in the $\mathrm{VB}_{0.5}$ sample. The XRD lines of $\mathrm{CoB}_{0.5}$ and $\mathrm{MoB}_{0.5}$ were in a similar pattern to that for $\mathrm{VB}_{0.5}$.

To reveal the basic electrochemical behavior of the as-prepared $\mathrm{MB}_{0.5}$ samples, $\mathrm{CV}$ s for $\mathrm{CoB}_{0.5}, \mathrm{MoB}_{0.5}$, and $\mathrm{VB}_{0.5}$, were measured. As shown in Figure 2, all three electrodes show two obvious current peaks in the positive scan, indicating at least two-step anodic oxidations in these

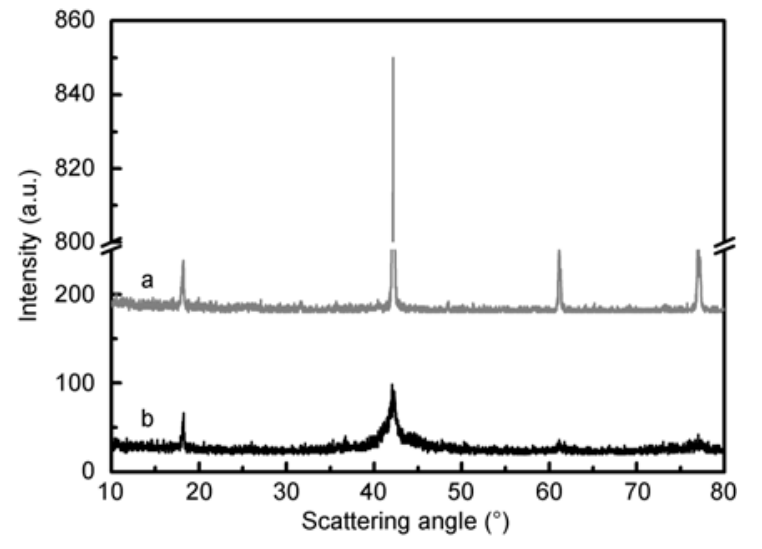

Figure 1 XRD patterns of (a) $\mathrm{V}$ and (b) $\mathrm{VB}_{0.5}$.

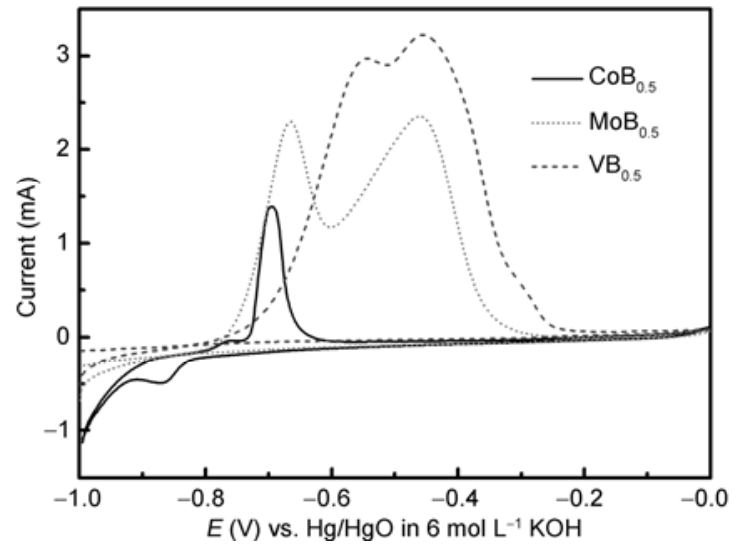

Figure $2 \mathrm{CVs}$ of the $\mathrm{MB}_{0.5}$ electrodes in a $6 \mathrm{~mol} \mathrm{~L}^{-1} \mathrm{KOH}$ solution. Potential sweep rate was set at $0.05 \mathrm{mV} \mathrm{s}^{-1}$.

samples. The two current peaks for $\mathrm{CoB}_{0.5}$ are located at -0.77 and $-0.70 \mathrm{~V}$, respectively. A reductive current peak is also found at $-0.86 \mathrm{~V}$ when the negative scan is imposed. The anodic peaks could originate from electro-oxidation of boron, cobalt, and the amorphous cobalt boride. In an alkaline electrolyte, the electro-oxidation of cobalt probably takes place as follows:

$$
\mathrm{Co}(\mathrm{OH})_{2}+2 \mathrm{e}^{-} \rightarrow \mathrm{Co}+2 \mathrm{OH}^{-}
$$

The standard equilibrium potential for this reaction is $-0.73 \mathrm{~V}$ vs. SHE [9]. The calculated equilibrium potential for cobalt in $6 \mathrm{~mol} \mathrm{~L}{ }^{-1} \mathrm{KOH}$ is about $-0.83 \mathrm{~V}$ vs. $\mathrm{Hg} / \mathrm{HgO}$ when the $\mathrm{pH}$ is greater than 14 . The onset potential for the two electro-oxidations of $\mathrm{CoB}_{0.5}$ shown in Figure 2 are -0.79 and $-0.74 \mathrm{~V}$. The first one is more negative than the equilibrium potential shown in eq. (1), indicating that the first current peak could not arise from cobalt electro-oxidation. Since the equilibrium potential of boron $(-1.79 \mathrm{~V}$ vs. SHE [9]) is more negative than the first onset potential, and boron is usually passivated in alkaline electrolytes, the first weak current peak could be attributed to the electro-oxidation of boron or amorphous cobalt boride. Consequently, the second strong anodic current peak should mainly or totally come from oxidation of cobalt (according 
to the discharge curve). The cathodic current peak for $\mathrm{CoB}_{0.5}$ should arise from electroreduction of $\mathrm{Co}(\mathrm{OH})_{2}$, since borate, the product of boron oxidation, cannot be reduced at this potential, according to the standard reductive potential of borate [9].

The two anodic current peaks of the $\mathrm{MoB}_{0.5}$ electrode are located at -0.67 and $-0.46 \mathrm{~V}$. The second current peak shows a large integrated area, suggesting a higher discharge specific capacity. The two anodic current peaks of the $\mathrm{VB}_{0.5}$ electrode are located at -0.55 and $-0.45 \mathrm{~V}$. Unlike the $\mathrm{CV}$ of $\mathrm{CoB}_{0.5}$, the two anodic current peaks for both $\mathrm{MoB}_{0.5}$ and $\mathrm{VB}_{0.5}$ overlap. Because the onset potentials of the current peaks for both $\mathrm{MoB}_{0.5}$ and $\mathrm{VB}_{0.5}$ are more positive than the equilibrium potential of their parent TM elements under the same conditions, it is difficult to determine the electro-oxidation reaction(s) producing the two current peaks simply from the CV curve.

Figure 3 compares the galvanostatic discharge curves of $\mathrm{CoB}_{0.5}$, the $\mathrm{B} / \mathrm{C}$ composite, and cobalt in $6 \mathrm{~mol} \mathrm{~L}^{-1} \mathrm{KOH}$ solution. The current density for both $\mathrm{CoB}_{0.5}$ and cobalt was set at $100 \mathrm{~mA} \mathrm{~g}^{-1}$, and the current density for $\mathrm{B} / \mathrm{C}$ was set at $50 \mathrm{~mA} \mathrm{~g}^{-1}$. The $\mathrm{CoB}_{0.5}$ electrode showed an open-circuit voltage of $1.06 \mathrm{~V}$ and a specific capacity of $245 \mathrm{mAh} \mathrm{g}^{-1}$ with a single discharge voltage plateau at about $0.75 \mathrm{~V}$. The shape of the discharge curve of elemental cobalt is similar to that of $\mathrm{CoB}_{0.5}$, but the discharge capacity, open-circuit voltage, and plateau voltage are much lower than those of $\mathrm{CoB}_{0.5}$. The $\mathrm{B} / \mathrm{C}$ composite electrode showed a voltage hump initially, followed by a voltage plateau at about 0.36 $\mathrm{V}$ at a discharge current density of $50 \mathrm{~mA} \mathrm{~g}^{-1}$. Although the boron-based cells have discharge capacities of $300 \mathrm{mAh} \mathrm{g}^{-1}$ and much lower voltage plateaus than those of cobalt- and $\mathrm{CoB}_{0.5}$-based cells, electro-activation of boron is clearly seen after ball-milling with conductive carbon, since elemental boron has no detectable discharge capacity under the same conditions. The activation of boron can be attributed to improved electronic conductivity as a result of combination with carbon. The appearance of a voltage hump at the

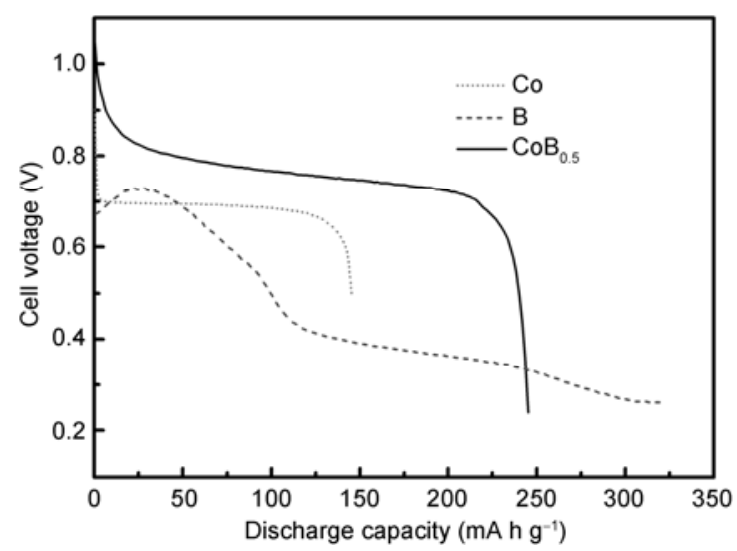

Figure 3 Galvanostatic discharge curves of cells using Co, B/C composite, and $\mathrm{CoB}_{0.5}$ anodes. The current densities are $50 \mathrm{~mA} \mathrm{~g}^{-1}$ for $\mathrm{B} / \mathrm{C}$, and $100 \mathrm{~mA} \mathrm{~g}^{-1}$ for $\mathrm{Co}$ and $\mathrm{CoB}_{0.5}$. beginning of the discharge curve for the $\mathrm{B} / \mathrm{C}$ composite is probably the result of surface passivation of boron; this was then alleviated by prolonged discharge. Comparison of the discharge curves shows that the $\mathrm{CoB}_{0.5}$ electrode demonstrates considerable electrochemical mutual activation of cobalt and boron. Although the theoretical capacity, as shown in Table 1 , is not achieved, the $\mathrm{CoB}_{0.5}$ electrode exhibits a much higher capacity and lower polarization than elemental cobalt does.

Figure 4 shows the discharge curve of $\mathrm{MoB}_{0.5}$. The open-circuit voltage is $0.94 \mathrm{~V}$, and two voltage plateaus appear at $\sim 0.7$ and $0.5 \mathrm{~V}$, in accordance with the two current peaks in the $\mathrm{CV}$. The discharge capacity from the first voltage plateau is about $500 \mathrm{mAh} \mathrm{g}^{-1}$, and the second one is about $850 \mathrm{mAh} \mathrm{g}^{-1}$, which is in agreement with the electronic quantities measured from the area of the current peak in the CV. As shown in Table 1, the capacity discharged from either of the voltage plateaus is larger than the theoretical capacity of boron, suggesting that neither of the voltage plateaus can solely originate from electro-oxidation of boron in $\mathrm{MoB}_{0.5}$. It is well known that molybdenum can be oxidized to multivalent molybdenum cations with valences from +3 to +6 by 3-6-electrons oxidations. Earlier work [10] reported that a mixture of $\mathrm{Mo}(\mathrm{VI})$ and $\mathrm{Mo}(\mathrm{V})$ is blue, and $\mathrm{Mo}(\mathrm{V})$ tends to disproportionate in solution. During the discharge process, the color of the electrolyte

Table 1 Capacity analysis of $\mathrm{MB}_{0.5}{ }^{\mathrm{a})}$

\begin{tabular}{|c|c|c|c|c|c|c|}
\hline \multirow[b]{2}{*}{$\mathrm{TMB}_{0.5}$} & \multicolumn{3}{|c|}{$\begin{array}{l}\text { Theoretical specific capacity } \\
\qquad\left(\mathrm{mAh}^{-1}\right)\end{array}$} & \multicolumn{3}{|c|}{$\begin{array}{l}\text { Experimental specific capacity } \\
\left(\mathrm{mAh} \mathrm{g}^{-1}\right)\end{array}$} \\
\hline & Total & From TM & From B & Total & $\begin{array}{c}\text { 1st } \\
\text { voltage } \\
\text { plateau }\end{array}$ & $\begin{array}{c}\text { 2nd } \\
\text { voltage } \\
\text { plateau }\end{array}$ \\
\hline $\mathrm{CoB}_{0.5}$ & 1457 & 833 & 624 & 245 & $\sim 0$ & $\sim 245$ \\
\hline $\mathrm{MoB}_{0.5}$ & 1983 & 1587 & 396 & 1388 & $\sim 500$ & $\sim 850$ \\
\hline $\mathrm{VB}_{0.5}$ & 3089 & 2376 & 713 & 2158 & $\sim 1430$ & $\sim 720$ \\
\hline
\end{tabular}

a) The theoretical specific capacity of $\mathrm{CoB}_{0.5}, \mathrm{MoB}_{0.5}$ and $\mathrm{VB}_{0.5}$ is calculated based on $\mathrm{Co}, \mathrm{Mo}, \mathrm{V}$ and $\mathrm{B}$, which are oxidized to $2^{+}, 6^{+}, 5^{+}$and $3^{+}$, respectively.

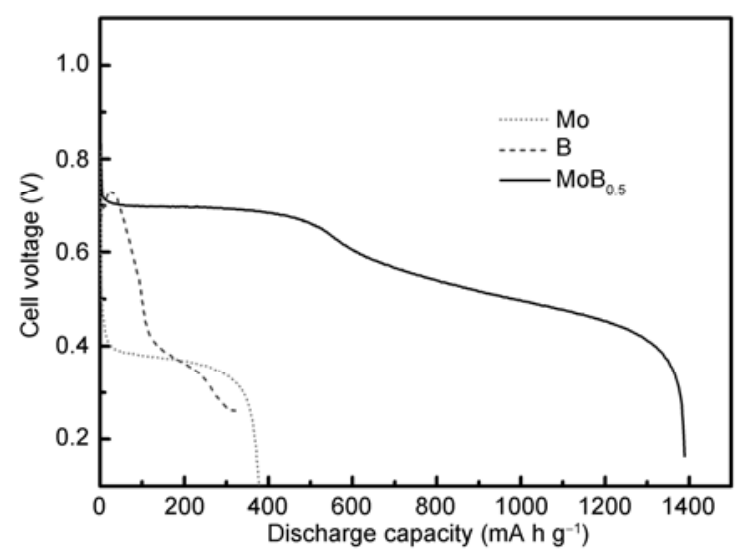

Figure 4 Galvanostatic discharge curves of cells using Mo, B/C composite, and $\mathrm{MoB}_{0.5}$. The current densities are $50 \mathrm{~mA} \mathrm{~g}^{-1}$ for $\mathrm{B} / \mathrm{C}$, and 100 $\mathrm{mA} \mathrm{g}^{-1}$ for Mo and $\mathrm{MoB}_{0.5}$. 
changed to blue and then became colorless, suggesting that most of the molybdenum in $\mathrm{MoB}_{0.5}$ is electro-oxidized to $\mathrm{Mo}^{5+}$ rather than to $\mathrm{Mo}^{6+}$. The theoretical oxidation capacity of molybdenum in $\mathrm{MoB}_{0.5}$ to $\mathrm{Mo}(\mathrm{V})$ is $1322 \mathrm{mAh} \mathrm{g}^{-1}$, which is lower than the experimental discharge capacity of $\mathrm{MoB}_{0.5}$. This suggests simultaneous activation of both molybdenum and boron in $\mathrm{MoB}_{0.5}$. The two voltage plateaus of the $\mathrm{MoB}_{0.5}$ electrode should therefore come from the electro-oxidation of molybdenum and amorphous $\mathrm{MoB}_{x}$, although it is difficult to determine the detailed reaction sequence. Compared with the experimental specific capacity of $370 \mathrm{mAh} \mathrm{g}^{-1}$ and the voltage plateau of $0.35 \mathrm{~V}$ for elemental molybdenum, $\mathrm{MoB}_{0.5}$ shows a much higher discharge capacity and much lower polarization.

The discharge curve of $\mathrm{VB}_{0.5}$ in Figure 5 shows an open-circuit voltage of $0.97 \mathrm{~V}$ and two clear voltage plateaus at 0.7 and $0.5 \mathrm{~V}$; this is in agreement with the CV results. According to the capacity analysis in Table 1, the experimental capacity is higher than the theoretical capacity if only boron is oxidized in $\mathrm{VB}_{0.5}$. This demonstrates that both boron and vanadium are electrochemically activated in the $\mathrm{VB}_{0.5}$ structure. Comparison of the discharge curves of elemental vanadium and $\mathrm{VB}_{0.5}$ shows that $\mathrm{VB}_{0.5}$ has a much lower polarization and higher discharge capacity than vana-

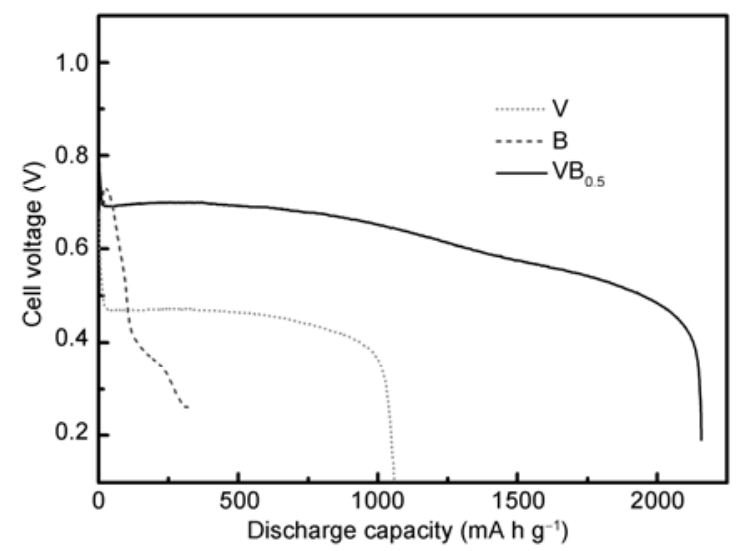

Figure 5 Galvanostatic discharge curves of the cells using V, B/C composite, and $\mathrm{VB}_{0.5}$. The current densities are $50 \mathrm{~mA} \mathrm{~g}^{-1}$ for $\mathrm{B} / \mathrm{C}$, and 100 $\mathrm{mA} \mathrm{g}^{-1}$ for $\mathrm{V}$ and $\mathrm{VB}_{0.5}$. dium does; this is similar to the cases of $\mathrm{CoB}_{0.5}$ and $\mathrm{MoB}_{0.5}$.

\section{Conclusions}

The $\mathrm{CoB}_{0.5}, \mathrm{MoB}_{0.5}$, and $\mathrm{VB}_{0.5}$ synthesized in this work show simultaneous electro-activation of both the TM and boron. The as-prepared borides have discharge capacities almost twice those of their parent TMs, and they have much lower polarizations. $\mathrm{CoB}_{0.5}$ shows one merged discharge voltage plateau originating from the electro-oxidation of cobalt and/or amorphous cobalt boride. Both $\mathrm{MoB}_{0.5}$ and $\mathrm{VB}_{0.5}$ show two discharge voltage plateaus originating from electro-oxidation of the TM and boride.

This work was supported by the Self-determined and Innovative Research Funds of Wuhan University of Technology, the Scientific Research Foundation for Returned Overseas Chinese Scholars, Ministry of Education, and the National Natural Science Foundation of China (20803057).

1 Wang Y, Ai X, Cao Y, et al. Exceptional electrochemical activities of amorphous Fe-B and Co-B alloy pow-ders used as high capacity anode materials. Electrochem Commun, 2004, 6: 780-784

2 Wang Y, Guang X, Cao Y, et al. Electrooxidation and dischargeability of transition-metal borides as possible anodic materials in neutral aqueous electrolytes. J Appl Electrohcem, 2009, 3: 1039-1044

3 Wang Y, Guang X, Cao Y, et al. Mechanochemical synthesis and electrochemical characterization of $\mathrm{VB} x$ as high capacity anode materials for air batteries. J Alloy Compd, 2010, 501: L12-L14

4 Licht S, Wu H, Yu X, et al. Novel alkaline redox couple: Chemistry of the $\mathrm{Fe}^{6+} / \mathrm{B}^{2-}$ super-iron boride battery. Chem Commun, 2007, 26: 2753-2755

5 Licht S, Ghosh S, Wang B, et al. Nanoparticle facilitated charge transfer and voltage of a high capacity VB2 anode. Electrochem Solid State Lett, 2011, 14: A83-A85

$6 \mathrm{Yu}$ X, Licht S. A novel high capacity, environmentally benign energy storage system: Super-iron boride battery. J Power Sources, 2008, 179: 407-411

7 Licht S, Yu X, Wang Y, et al. The super-iron boride battery. J Electrochem Soc, 2008, 155: A297-A303

8 Bard A J, Parsons R, Jordan J. Standard Potentials in Aqueous Solution. New York: Marcel Dekker, 1985. 799

9 Milazzo G, Caroli S, Sharma V K. Tables of Standard Electrode Potentials. New York: John Wiley \& Sons, 1978. 115

10 Shen P W, Che Y X, Luo Y J, et al. Inorganic Chemistry Series. Vol. 8. Xi'an: Science Press, 1984. 470

Open Access This article is distributed under the terms of the Creative Commons Attribution License which permits any use, distribution, and reproduction in any medium, provided the original author(s) and source are credited. 